\title{
La incidencia del conflicto en el diseño político-normativo del rol del Estado: el caso de la (des)construcción del rol ambiental del Estado Chileno.
}

\author{
The conflict impact on the political-normative design in State's role: the Chilean Republic \\ environmental role, a case of (dis)construction
}

\author{
Carlos Rungruangsakorn L.*
}

Resumen: El presente artículo pretende conectar la teoría conflictualista liberal con la construcción del rol del Estado. En este marco, se analiza el modelo teórico desarrollado por Oszlak (2011) el cual explica cómo se expresa el rol del Estado en tres niveles de acción: micro, meso y macro.

A partir de lo anterior, se examina el proceso del diseño político-normativo en que se expresa formalmente el papel estatal en una determinada materia. Junto con ello, y para una mejor compresión del cómo se gesta el rol estatal, se propone un esquema teórico dialectico denominado "Ciclo de la (des) construcción del rol del Estado", el que sirve de base para analizar el caso de la conformación del rol ambiental del Estado Chileno con un énfasis en el sistema de evaluación de impacto ambiental.

Palabras clave: Rol del Estado, conflicto, diseño político-normativo, fricción dinámica del diseño, rol ambiental, socioambiental.

\begin{abstract}
This article aims to connect the liberal conflict theory with state role construction. In this framework, the theoretical model developed by Oszlak (2011) is approached, which explains how the state role is expressed in three levels of action: micro, meso and macro.

From the above, the process of political-normative design is examined whereby the state's role in a given matter is formally manifest. For a better understanding of how the state role is created, a dialectical theoretical scheme called "Cycle of the (des)construction of the role of the State" is proposed. Subsequently, this model is applied for analyze the environmental role conformation of Chilean State, with an emphasis on its environmental impact assessment system.
\end{abstract}

Keywords: Role of the State, conflict, political-normative design, dynamic friction of design, environmental role, socio-environmental.

Recibido: 7 enero 2019 Aceptado: 19 mayo 2019

\footnotetext{
* Chileno. Académico del Instituto de Asuntos Públicos de la Universidad de Chile. Doctor en Ciencias Sociales de la Universidad Nacional de Cuyo de Argentina, Magíster en Asentamientos Humanos y Medio Ambiente de la Pontificia Universidad Católica de Chile. Correo electrónico: profesor.rsakorn@gmail.com
} 


\section{1.- Introducción: La teoría conflictualista liberal en función al rol del Estado y el propósito de la investigación.}

La teoría conflictualista liberal, en su abordaje científico social cubre un amplio campo de conflictos. Su objeto de estudio son los grupos sociales e indaga sobre sus intereses, valores o creencias en función de la disputa en cuestión, pero por sobre todo, su eje de análisis es el poder como elemento central del conflicto, por cuanto determinaría la dinámica de éste, pudiendo generar efectos en los grupos tales como la desaparición, negociación, absorción, eliminación o la subordinación, entre otros ${ }^{1}$.

Esta corriente teórica realza que la principal función social del conflicto es la promoción del cambio social lo que, de una u otra forma, imbricaría el quehacer del Estado. En este cuadro, es sustancial sostener que el Estado está lejos de ser una entidad única, sólida y discursivamente antropomórfica. Al contrario, se encuentra sometido a diversas fuerzas que le penetran, interactúan o le resisten, las que inevitablemente influyen en el funcionamiento diario de la administración pública ${ }^{2}$.

El Estado como organización, convive con otros actores que incluso pueden poner en jaque su funcionamiento a pesar de gozar del monopolio de la fuerza y la concepción weberiana, de una obediencia ipso facto e incondicional. Es decir, el Estado se enfrenta a una serie de presiones que influyen en el ejercicio de sus roles y, en consecuencia, en los diseños políticos-normativos que se pactan. En este sentido, el poder existe y se encuentra también en lugares fuera del Estado, como, por ejemplo, en las clases o los grupos sociales ${ }^{3}$. Por lo tanto, el Estado no sería por derecho propio superior a todos los demás actores, aunque permanentemente aspire a serlo y especialmente por quienes les toca su conducción o gobierno. Es más, el Estado se encuentra en un plano de competencia al interior de sí mismo, así como también con otras organizaciones.

Aunque suene de perogrullo, el Estado es una organización social que funciona por medio de instituciones compuesta por funcionarios, los cuales también son ciudadanos miembros de la sociedad. En efecto, estos no están exentos de pertenecer a grupos tales como las elites, de interés, movimientos sociales o partidos políticos, los que pueden promover diferentes versiones de cómo debería funcionar el Estado en las diversas materias que le conciernen, generándose con ello posibles focos de permanente conflicto o tensión al interior del aparato estatal y que, en la cotidianeidad, es sostenida por los funcionarios-ciudadanos ${ }^{4}$.

Sin perjuicio de lo anterior, es necesario resaltar que el Estado no es una entidad estática, al inverso, es una entidad dinámica que sigue un derrotero conforme a los valores y sistemas de vida que produce y reproduce la sociedad que le sostiene en un espacio y tiempo determinado. Sin embargo, los tiempos estatales, las resistencias a los cambios, la propia burocracia y los grupos de interés, son parte de un esquema que no permite necesariamente, por ejemplo, una coincidencia relativamente armónica entre las nuevas demandas sociales y la oferta político-normativa del Estado.

\footnotetext{
1 Pedro-Luis Lorenzo, Principales Teorías sobre el Conflicto Social. Revista Historia, Norba 15, España, 2001, 237-254; Arturo Contreras, Los Estudios del Conflicto: una necesidad en la era post moderna. Revista Política y Estrategia No 91, Chile, 2003, 9-34; Roberto Domínguez y Silvia García, Introducción a la Teoría del Conflicto en las Organizaciones, Working Papers 48, Universidad Rey Juan Carlos, España, 2003, 1-48; Luís García, Diego Muñoz y Juan Gómez, Aportes teóricos al concepto de conflicto social: una lectura desde las macro y microsociologías hasta los modelos integradores emergentes, Revista Virajes. № 8, Colombia, 2006, 17-47; Germán Silva, La teoría del conflicto. Un marco teórico necesario, Prolegómenos Derechos y Valores, vol. XI, N²2, Bógota, 2008, 29-43; Matthew Levinger, Conflict Analysis: Understanding Causes, Unlocking Solutions, United States Institute of Peace Academy Guides edition, USA, 2013.

2 Nicos Poulantzas, Estado, Poder y Socialismo. Ed. Siglo XXI, México, 1979, 35-39; Samuel Huntington, El orden politico en la sociedad del cambio, Paidós, España, 1979, 13-39; Rosemary O’Leary, The Ethics of Dissent, Ed. CQ Press, USA, $2006,4-25$.

3 Poulantzas, op. cit. 35-49; Ralf Dharendorf, The Modern Social Conflict, Transaction Publishers, USA, 2008, 23-37.

4 Poulantzas, op. cit.; Huntington op. cit;; Migdal, op. cit.
} 
Profundizando, la expectativa y reivindicación de la población normalmente crece más rápido que la capacidad de los gobiernos para satisfacerlas, generando conflictos o inestabilidad, en un mundo globalizado donde la movilidad y la comunicación agudizan la comparación racional del bienestar y los derechos. Este proceso se da, especialmente, en sociedades con mayor presencia de clases medias las que tienen expectativas crecientes de mejora, y que no están dispuestas a retroceder en los logros alcanzados producto de la reformulación de los pactos sociales y las políticas públicas generadas en democracia 5 .

Una de las reivindicaciones sociales emergentes en Chile dice relación con la temática ambiental, lo que se refleja en el constante incremento de los procesos de judicialización de los conflictos socioambientales en el sistema de evaluación de impacto ambiental, SEIA, tal como se indica en la tabla 1

Tabla 1: Porcentaje de judicialización de los Proyectos con estudio de impacto ambiental favorable, según período de gobierno.

\begin{tabular}{|l|c|c|}
\hline \multicolumn{1}{|c|}{ Presidencia } & $\begin{array}{c}\text { Periodo de levantamiento } \\
\text { datos }\end{array}$ & $\begin{array}{c}\text { Porcentaje de } \\
\text { judicialización }\end{array}$ \\
\hline Ricardo Lagos & $2000-2006$ & $11 \%$ \\
\hline Michelle Bachelet & $2006-2010$ & $22 \%$ \\
\hline Sebastián Piñera & $2010-2014$ & $29 \%$ \\
\hline Michelle Bachelet & $2014-2016$ & $45 \%$ \\
\hline
\end{tabular}

Fuente: Elaboración propia, sobre la base de los datos publicados por el Servicio de Evaluación de Impacto Ambiental de Chile, 2017

Como se puede observar, el incremento de la judicialización de los proyectos de inversión productiva en la presente década, es un claro indicador que los conflictos socioambientales no encuentran en el órgano ejecutivo chileno canales de resolución de estos, por ende, se acude a otro poder del Estado para que las demandas locales o de los afectados logren ser evaluadas y consideradas por el órgano judicial.

Reforzando el punto anterior, Chile es uno de los países con mayor presencia de conflictos socioambientales a nivel mundial, alcanzando el lugar 14 de 181 países del Atlas de Justicia Ambiental $2018^{6}$, producto de proyectos principalmente vinculados a energética, minera y pasivos ambientales.

Por otra parte, la Comisión de Productividad de la Confederación de la Producción y del Comercio (CPC), organismo que agrupa a las federaciones de empresarios y comerciantes del país en su estudio del 2017, indicó que el 90\% de la inversión en grandes proyectos, equivalente a 7.721 millones de dólares, es decir, el 88.9\% de la inversión aprobada se encuentra judicializada7.

En consecuencia, frente a una iniciativa de inversión productiva, se puede observar que la relación que se desarrolla entre privados, sociedad civil y Estado tiene un componente de alta complejidad por cuanto se producirían conflictos socioambientales cuya gestión puede derivar en soluciones fuera del diseño político-normativo de la institucionalidad ambiental, generando un

\footnotetext{
${ }^{5}$ Huntington op. cit.; Moisés Naim, El Fin del Poder. Ed. Debate, Santiago, 2013, 15-44.

${ }^{6}$ Luis Cordero, Valentina Durán, Camila Palacios, Violeta Rabí, Andrea Sanhueza y Anahí Urquiza, Derribando mitos: propuestas para mejorar el acceso a la justicia ambiental, Espacio Público, Memo de políticas públicas No13, 2018, 3-5. Disponible en https://www.espaciopublico.cl/wp-content/uploads/2017/12/memo-N13-justicia-ambiental-FINAL.pdf; Ver también en sitio web del atlas https://ejatlas.org/country

${ }_{7}^{7}$ Corporación de la Producción y el Comercio, Proyecto de inversión en el SELA, Observatorio de la Productividad, Informe $\mathrm{N}^{\circ} 5$, Santiago, 2017, 1-10. Disponible en

http://www.productividadchile.cl/wp-

content/uploads/2017/07/Informe_5_2T17_Proyectos_de_Inversion_en_el_SEIA.pdf. Revisado el 5 de enero de 2019.
} 
debilitamiento de esta y una mayor disputa. De allí la importancia de abordar esta temática por sus implicancias: sociales, económicas, políticas y ambientales.

Dado que el fenómeno de los conflictos socioambientales sigue en permanente incremento en un contexto de crisis ambiental ${ }^{8}$, entender el SEIA desde la perspectiva del diseño político-normativo y la teoría liberal del conflicto, permite tener un análisis alternativo sobre el papel del Estado en esta materia. Especialmente cuando en menos de 8 años de la creación de la institucionalidad ambiental, el SEIA sea el foco de nuevas reformas.

Expuesto el marco anterior, el presente trabajo de investigación aspira a contribuir en la descripción y comprensión de la trayectoria del diseño político-normativo en que se explicita el papel ambiental del Estado chileno, con un especial énfasis en el SEIA.

Por otro lado, la hipótesis en particular que pretende sostener este estudio, es que el diseño político-normativo del rol del Estado en el SEIA, se encuentra marcado por un proceso dialectico cuyo resultado contiene fricciones que podrían intensificar los conflictos socioambientales que emergen en el proceso de evaluación de los estudios de impacto ambiental por parte del órgano ejecutivo. Lo anterior no sin antes de entender el concepto de "rol del Estado" y otorgar una explicación alternativa, desde la teoría liberal del conflicto, sobre la construcción del papel estatal mediante el esquema teórico: "Ciclo de la (des)construcción del rol del Estado".

\section{2.- El rol del Estado y los conflictos}

El conflicto promueve la transformación y la creación del rol estatal en una determinada materia, éste sería un catalizador esencial en el cambio del diseño o la incorporación de nuevas líneas políticasnormativas que desarrollan tanto el órgano ejecutivo como el legislativo para el funcionamiento del Estado y su sociedad.

El rol del Estado está permeado por factores valóricos e ideológicos, los cuales determinan el cómo y en qué grado interviene en la realidad social, pero ¿qué implica el concepto: "rol del Estado"? Desde un punto de vista conceptual, para Oszlak el rol del Estado:

Es el papel atribuido a una o más de sus instituciones en la producción de bienes, regulaciones o servicios destinados a resolver ciertas cuestiones problematizadas que plantea la organización o el funcionamiento de una sociedad, así como los impactos y consecuencias que se derivan de esas formas de intervención sobre la correlación de poder y la distribución del producto en esa sociedad"’.

Analizando la definición, cuando Oszlak se refiere a "papel atribuido a una o más instituciones" se puede interpretar desde dos focos: uno jurídico y otro político. Desde el punto de vista jurídico, el papel del Estado se refiere a las competencias y facultades que se le ha asignado normativamente a una institución para su funcionamiento. Y por otro, el rol político implica el nivel de intervención y de actividad que le imprime el gobierno de turno, según su programa e ideología. Asimismo, el rol del Estado es esencialmente un proceso de toma y concreción de decisiones u operaciones vinculadas a las competencias propias de las instituciones cuyo fin es resolver, regular o satisfacer demandas de la sociedad vinculadas con las temáticas propias de la institución.

Para Oszlak, el rol del Estado puede analizarse desde tres niveles diferentes, cada una de ellas estrechamente vinculadas entre sí.

\footnotetext{
8 Fernando Estenssoro, Crisis ambiental y cambio climático en la politica global: un tema crecientemente complejo para américa latina. Universum (Talca), 2010. 57-77. Disponible en https://dx.doi.org/10.4067/S0718-23762010000200005

9 Oscar Oszlak, El Rol del Estado: Micro, Meso, Macro. Conferencia Dictada en el VI Congreso de Administración Pública Organizado por la Asociación Argentina de Estudios de Administración Pública y la Asociación de Administradores Gubernamentales, Resistencia del Chaco, Argentina, 2011, p.5.
} 
a) Nivel Micro: en donde el rol del Estado puede interpretarse desde la perspectiva cotidiana y la experiencia individual de sus habitantes. El Estado se hace presente en el tejido social y diariamente con múltiples y heterogéneos servicios, bienes, actividades y regulaciones. En este quehacer, el Estado, a través del tiempo puede cambiar sus servicios, reorientarlos, profundizarlos o eliminarlos.

b) El Nivel Meso: está orientado a los contenidos y orientaciones de las políticas públicas de quienes representan al Estado, es la parte más concreta y tangible del papel del Estado. En el nivel meso es donde se ubica la "Agenda Social", entendida como el conjunto de necesidades y demandas de las que se hacen cargo determinados actores sociales, adoptando decisiones y llevando a cabo acciones tendientes a satisfacerlas. El Estado, en especial el poder Ejecutivo, mediante sus instituciones desarrolla una serie de acciones para tratar de resolver la problemática planteada en la agenda social, incorporándolo a su propia agenda, (Agenda Estatal), siempre y cuando los decidores y las facultades que le otorgue la ley lo determinen como pertinente. El grado con que el Estado prioriza y enfatiza en la solución de la agenda se realiza por medio de los recursos de sus instituciones, lo que se verá influido por el volumen de la problemática, las consecuencias, y el valor público que le dé la sociedad.

Profundizando lo anterior, Oszlak indica lo siguiente:

Las tomas de posición de quienes actúan en nombre del estado asumen su representación las indican, con mayor claridad, cuáles son las orientaciones político-ideológicas implícitas en sus acciones. Estas tomas de posición constituyen, en los hechos, las políticas públicas o políticas estatales de las agencias responsables de resolver las cuestiones agendadas"10.

Las tomas de posición generan consecuencias positivas o negativas en su proceso de resolver la Agenda Estatal, pueden existir actores sociales favorecidos o perjudicados; pueden generar distintos grados de clima social negativo entre los actores sociales afectados generándose derivadas para "reagendar". Reforzando esta idea, Poulantzas indica que la ideología en el aparato estatal, "no solo dice la verdad, declama la verdad de su poder, sino que asume igualmente los medios de elaboración y de formulación de las tácticas políticas. Produce saber y técnicas de saber imbricadas en la ideología."11. Además, las tomas de posición pueden generar la creación de una o varias agencias estatales para implementar la solución o, si ya existen, puede implicar la entrega de nuevas facultades y la asignación de recursos para que estas instituciones aborden la problemática.

c) El nivel Macro: es el más abstracto de los niveles anteriores, es donde las decisiones y acciones estatales reflejan orientaciones de política que, a la par de definir los alcances y densidad de la intervención de sus instituciones, tienen profundas consecuencias sobre la organización social existente.

Este nivel se caracteriza por:

- Incorporar las relaciones de poder y vínculos de dominación entre los actores económicos, políticos y grupos de interés.

- Expresar una cierta modalidad de división social del trabajo según la cual el Estado, asume un conjunto de responsabilidades cuyo ejercicio y resultados afectan la suerte relativa de los diferentes sectores de la sociedad.

- Las orientaciones de la política estatal fijan las coordenadas para la extracción y asignación de recursos (públicos y privados), en función de criterios de equidad distributiva que, en

10 Oszlak, op. cit., p.8.

11 Poulantzas, op. cit., p. 70. 
última instancia, afectan el ingreso, la riqueza, las oportunidades y/o las condiciones de vida de diferentes sectores sociales.

El nivel Macro se destaca porque el Estado actúa en aquellas sociedades en donde se requiere la intervención de este para mesurar las desigualdades sociales y conflictos distributivos propios de sociedades capitalistas. Es así donde el Estado entra a operar en lo que denomina Oszlak, pactos fundacionales del capitalismo, entendido por pacto "un conjunto de reglas de juego vigentes en una sociedad" en que el Estado opera ejerciendo su monopolio coercitivo y su gestión sobre esas reglas.

Existen tres tipologías de pactos. El primero de ellos es el "Pacto de Dominación", en donde las sociedades capitalistas se organizan en torno a un pacto político que fija las reglas de juego fundamentales que gobiernan las relaciones entre las sociedades y sus estados, la cuestión central consiste en definir, en cada momento, de qué modo se asegurará un contexto que facilite la convivencia, regule el conflicto y, sobre todo, permita el mayor desarrollo de las fuerzas productivas de la sociedad. El segundo pacto es el "Funcional", es donde se define quiénes son los agentes fundamentales del proceso de acumulación de capital, a quiénes deben confiarse las funciones de establecer y reproducir las condiciones que permitan el desarrollo de las fuerzas productivas o en manos de quiénes debe estar la decisión sobre el destino de los excedentes que genera la actividad económica. El último es el "Pacto Distributivo" en el cual el Estado interviene o no en la repartición de las riquezas, beneficios, costos y externalidades. En esta dinámica ciertos actores ganan, otros pierden y, por lo tanto, la sociedad experimenta una redistribución de sus recursos materiales, amparada y recreada por las propias reglas del juego que gobiernan las relaciones entre ésta y el Estado.

Sin perjuicio de lo anterior, es importante destacar que existen otras tipologías de pactos que escapan al concepto de Ozlack. En este sentido, se destaca a Elinor Ostrom la cual, en su obra, "El Gobierno de los Bienes Comunes"12, desarrolla un profundo análisis de la gobernanza de los bienes comunes, en que el Estado juega un rol mínimo en la administración o el uso de recursos comunes. Un ejemplo, entre otros que destaca Ostrom, es la figura de los ejidos mexicanos, donde prima la interacción entre los sujetos en el usufrutuo y la autogestión de la tierra que le es común a una comunidad, cuyo proceso se genera una repartición de riqueza sin la intervención del Estado ${ }^{13}$. Claramente esto escapa de las dinámicas de dominación de Ozlack.

En suma, los niveles Macro, Meso y Micro actúan como subsistemas recursivos y dinámicos entre sí y en sí mismos, todos ellos conforman el sistema denominado Rol del Estado, en el que esta totalidad, a su vez, interactúa dinámicamente con la sociedad para imponer o generar una posición en la pugna del poder que en las sociedades capitalistas generan las profundas desigualdades.

Aun así, llama la atención que el modelo de Oszlak olvide la idea que el Estado, en general, es un sistema abierto ${ }^{14}$, por cuanto recibe influencias externas que lo modifican o mantienen el statu quo. Los factores externos que influyen en el rol estatal se encuentran en fenómenos como la globalización, los intereses geopolíticos o económicos de otros estados y organismos internacionales, por ejemplo, el Banco Mundial, la Organización de las Naciones Unidas, entre otros.

Sin perjuicio de lo anterior, para efectos de este trabajo, se concebirá el rol del Estado como el producto de un proceso que se caracteriza por la asignación de un fin y de facultades a una entidad pública con respecto a un determinado objeto, cuyos alcances y limitaciones se encuentran definidos en el diseño político-normativo, construido por quienes ejercen el poder político en un momento dado.

12 Elinor Ostrom. El gobierno de los bienes comunes. La evolución de las instituciones de acción colectiva. México, UNAM-CRIM-FCE, 1395.

13 Alvaro Ramis, El Concepto de Bienes Comunes en la obra de Elinor Ostrom, Ecología politica, 2013, 116-212, disponible en https://www.ecologiapolitica.info/novaweb2/wp-content/uploads/2015/12/045_Ramis_2013.pdf

14 William H. Newell and Jack W. Meek, What Can Public Administration Learn from Complex System Theory? Administrative Theory \& Praxi \& Praxis, Vol. 19, No. 3 (1997), pp. 318-330; Morton A. Kaplan, Systems Theory and Political Science, Social Research, Vol. 35, No. 1, Focus—Trends and Issues in American Political Science (SPRING 1968), 30-47. 
Que el rol del Estado sea el resultado de una asignación de un fin y de facultades a una entidad pública, implica que el papel diseñado tiene un componente concreto que se expresa en servicios, procesos o productos que condicionan un determinado sector u objeto de gestión, por ejemplo, energético, inversión, productivo, educación, ambiente, entre otros. El diseño político-normativo de ese rol, será una expresión tanto ideológica como de los intereses de quienes detenten el poder de turno, los que serán reflejados en el marco normativo y el ejercicio en el quehacer de una determinada institución en función al objeto en cuestión.

\section{3.-Ciclo de la (des) construcción del rol del Estado. Una propuesta teórica.}

El rol del Estado expresado materialmente en el diseño político-normativo, tiene un ciclo de desarrollo que va desde su génesis hasta su puesta en marcha y que, dependiendo de la temática a regular, estaría enmarcado en mayor o menor medida por el conflicto. Por ejemplo, medidas vinculadas con la salud e higiene de calles, tienen un menor nivel de conflictividad que aquellas que están relacionadas con la incorporación de nuevos impuestos.

Tal como se ha indicado a lo largo de este trabajo, el conflicto promueve la transformación y la creación del rol estatal en una determinada materia, fomenta el cambio del diseño o la incorporación de nuevos diseños políticos-normativos que desarrollan tanto el órgano ejecutivo como el legislativo. Sin embargo, ¿cuáles son las causas profundas que producen la necesidad de un nuevo diseño o el cambio de éste?

Cabe destacar que los diseños políticos-normativos como objeto, una vez elaborados, presentan una rigidez, propia del derecho público, que no es posible cambiar en el corto plazo, por ello es un proceso significativamente complejo y delicado. Gramsci15 ya en 1917 lo había mencionado advirtiendo que, si un político se equivoca en su hipótesis sobre la necesidad de la vida de los hombres, se corre el riesgo de la revolución.

Por eso, aprobar una normativa, en un régimen democrático requiere de inteligencia, negociación, consenso y compromisos políticos cuyos resultados tratan de satisfacer las ideologías, intereses o valores de los actores y grupos involucrados.

Hay que recordar que también la prioridad de un diseño es la resultante de una competencia entre diseños que son políticamente jerarquizados según su importancia en la agenda, ya sea por el ejecutivo o por el legislativo. Además, se debe entender que los gobiernos por medio de sus programas tienen la capacidad de problematizar y proponer normas para abordar una determinada temática que consideren como importante.

Una vez que el diseño político-normativo entra en operación, generalmente, no presenta una caducidad inmediata por lo que puede trascender por décadas. Sin embargo, el diseño políticonormativo desarrollado emerge en un contexto histórico, político, social, valórico y económico determinado, en que, a medida que pasa el tiempo sumado a las trasformaciones sociales, se puede presentar el fenómeno del "desacople político-normativo". Es decir, cuando el diseño políticonormativo ya no responde como un adecuado satisfactor ${ }^{16}$ a las nuevas necesidades en el ámbito de los intereses, valores o el cambio cultural que vive una sociedad, entonces, se genera el replanteamiento del rol del Estado en la materia en cuestión, es decir, el significado del objeto se ha desvalorizado. Con esto se produce la respectiva dinámica del conflicto que motiva al rediseño o el reemplazo del obsoleto diseño político-normativo.

En segundo lugar, las "materias emergentes" son otra causal que influye en plantear nuevos roles para el Estado, especialmente cuando éstas generan impactos no deseados en gran parte de la

15 Antonio Gramsci, Odio a los Indiferentes, Editorial Ariel, Buenos Aires, 2018, 21-25

16 Manfred Max-Neef, Desarrollo a escala bumana: Conceptos, aplicaciones y algunas reflexiones, Icaria Editorial, España, 1993, 55-68. 
sociedad, como, por ejemplo, "cambio climático", "migración”, entre otros. En este sentido, aparecen nuevos objetos cuya valoración generan disputas.

Tanto en el fenómeno del "desacople político-normativo" como en las "materias emergentes", subyacerán y se presentarán una variedad de causas, dinámicas y estrategias conflictivas que determinarán la construcción o desconstrucción de rol que adquirirá el Estado en la temática en pugna.

Es significativo indicar, que el diseño político-normativo en su fase de operación, puede sufrir una tercera anomalía o derivada que se le podría denominar "fricción del diseño". La fricción es un contacto mediante el roce entre dos cuerpos que, dependiendo de la imperfección entre ambas superficies puede generar un determinado coeficiente de rozamiento ${ }^{17}$. Este fenómeno físico, es extrapolable al diseño político-normativo, que dependiendo de su imperfección en su contacto con la realidad o materia que pretende regular, puede generar distintos grados de fricción o divergencia que, desde el punto de vista de las ciencias sociales, se manifiestan como conflictos. Cabe preguntarse, ¿qué elementos del contacto entre el diseño y la realidad pueden generar conflicto?

Varios elementos incidirían en la "fricción del diseño" y se podrían categorizar en dos ámbitos: 1) Los implícitos o aspectos de fondo, tales como: los valores, la inequidad, los seudo satisfactores, el poder, ideología, los intereses, entre otros; y 2) Los explícitos, donde las fricciones se manifiestan en modos concretos de: gobierno de guerrillas ${ }^{18}$ corrupción, tráfico de influencias, reclamos, buropatología, sabotajes y otros reclamos públicos sobre la ineficiencia e ineficacia del diseño.

La fricción del diseño tiene la peculiaridad de ocurrir en el ámbito de los funcionarios ejecutores o "Street-Level Bureaucrats", es decir, los que aplican el diseño político-normativo y, en consecuencia, desarrollan o mantienen activo el rol del Estado. A diferencia de lo que plantea Oszlak, el rol del Estado a nivel Micro no solo es el lugar de recepción de los costos/beneficios de las actividades del Estado, sino que también es el área donde se expresan, en forma tangible, los conflictos en la aplicación de los diseños políticos-normativos, y donde surge el respaldo o el cuestionamiento al rol del Estado por parte de la sociedad civil.

$\mathrm{Si}$ el diseño político-normativo se ajusta a las expectativas de los actores involucrados y presenta una adecuada ejecución por parte del aparato público, entonces tendrá una fricción mínima que conducirá hacia una estabilidad en su funcionamiento. Esta situación de "funcionamiento armonioso del diseño", durará hasta que cambien las expectativas de los actores o comience un proceso de deterioro en su ejercicio. La sumatoria de las fricciones dinámicas del diseño, según su gravedad, pueden gatillar en un desacople político-normativo.

Cabe mencionar que un Estado que tenga o registre varios conflictos sociales, no implica que sea un "estado débil" en el sentido que le otorga la obra Migdal19 o que su "estatalidad" desde la perspectiva de Fukuyama ${ }^{20}$ sea precaria, al contrario, la totalidad de los Estados registran fallos de variado tipo, que crean tensiones disfuncionales en su actividad hacia dentro o hacia fuera, o en ambos sentidos ${ }^{21}$.

Se podría aventurar a decir que, un Estado débil tiene crisis en cambio un Estado normal tiene conflictos. Sin embargo, si los conflictos se vuelven estructurales, se generalizan y no se gestionan, entonces los Estados comienzan un proceso de crisis y se convierten en Estados fallidos, capturados, incapacitados, fracturados o disfuncionales. ${ }^{22}$

17 Ignacio Bragado, Física General, Ed. Universidad de Valladolid, España, 2004, 37.

18 O’Leary, Op. cit., 5.

${ }^{19}$ Joel Migdal, Estados débiles, Estados fuertes, Ed. Fondo Cultura Económica. México, 2011, 67-92.

20 Francis Fukuyama. (2004). La Construcción del Estado. Ediciones B. Barcelona. España, 21-32.

21 Antonio Sánchez-Guijón, Estados fallidos, Estados matones y estabilidad global, 2003, Nueva Revista número 085. Madrid-España, 27-39.

22 Jonathan Di John, Conceptualización de las causas y consecuencias de los Estados fallidos: una reseña crítica de la literatura, Revista de Estudios Sociales No 37, 2010, 46-86, disponible en http://journals.openedition.org/revestudsoc/12528b 
En fin, considerando que los diseños normativo-políticos pueden producir conflictos, entonces es necesario plantear la pregunta: ¿Qué papel le cabe al Estado en esta temática?

Las organizaciones estatales están sometidas a un permanente conflicto ya sean latentes o activos. Estos pueden emerger tanto entre el legislativo, el ejecutivo y el judicial como en el propio espacio de cada uno de estos órganos. Estas entidades, tal como cualquier otra, tanto en su estructura organizativa como en su operación presentarán diversos tipos de conflictos ante los cuales el Estado desarrollará distintos papeles, ya sea como mediador, actor presente o ausente, promotor o desarticulador del conflicto. Cualquiera sea la posición que tome, éste tendrá como denominador común el factor del poder.

Entonces, el rol del Estado en los conflictos estaría marcado por el ejercicio del poder que realizan los ocupantes de los cargos públicos de la Administración pública, cuyo actuar se debería guiar sobre la base del diseño político-normativo, que les otorga las facultades que les permite actuar legítimamente en la sociedad.

Sin embargo, los que detentan los cargos de turno, en especial en el órgano ejecutivo, basaran sus decisiones en la conservación u obtención de mayor poder para sus intereses o ideología. Dependiendo de la importancia social de la cartera o entidad, estarán flanqueados por los grupos de interés y la opinión pública.

En el caso del Ejecutivo, el grupo político que se encuentre a cargo de su dirección podrá potenciar o debilitar el diseño político-normativo que está en marcha. Quien detente el poder, podrá reproducir el diseño político-normativo vigente o producir uno nuevo, todo dependerá de cómo el diseño ayude a conservar o potenciar su poder. Si la relación entre el diseño y los beneficios políticos o intereses le reditúa un mayor poder con un bajo nivel de conflicto, entonces el gobernante seguirá reproduciendo o potenciando el diseño. Si esta relación no le reditúa nada en términos del poder y no es afectado por el conflicto, entonces el gobernante podría mantener o modificar el diseño. Sin embargo, si el diseño le genera un alto nivel de conflicto y ve mermado su poder, entonces generara una serie de estrategias para cambiar o anular al diseño y de paso el conflicto, como, por ejemplo, mediante una escasa asignación presupuestaria, disminución del personal, establecimiento de barreras burocráticas, entre otras tácticas. Por lo tanto, utilizará el aparato público tanto para controlar el rol según su conveniencia.

Otro variable substancial a considerar y que no está tratado en la teoría del conflicto, es la publicidad del conflicto, la cual está vinculada con dos variables: control y difusión. Cuando el conflicto es "intra-muro" implica la posibilidad de un mayor control y conducción por parte de quien arbitra o es la parte interpelada. Si se rompe la frontera, es decir, pasa al ámbito público, entonces el conflicto pasa a ser "extra-muro" entrando a jugar una nueva variable que es la presión "pública" y el potencial involucramiento de nuevos actores los cuales podrán generar alianzas con una u otra parte. En consecuencia, cuando hay una asimetría en el poder en la disputa interna, la parte más débil puede acudir a la táctica de publicitar el conflicto para ganar adeptos.

Si lo anterior se lleva a la esfera del Estado, y en especial en el poder Ejecutivo, este tenderá a que el conflicto se maneje "intra-muro", tratará de evitar la publicidad a fin de no perder poder y control. El interpelante, frecuentemente en una posición más débil, tendrá presente el uso de la publicidad en el proceso de diálogo o negociación con el gobierno que conduce el Ejecutivo. Si el conflicto se torna "extra-muro", se constituirá una advertencia de que el poder del ejecutivo ha mermado. En suma, el rol del Ejecutivo en el conflicto estará condicionado en cómo le afecta el diseño político-normativo a la administración de turno en su: poder, sus intereses, ideología y la relación con otros actores. Con todo, sus decisiones podrán ser impuesta por el "legitimo" uso de la fuerza, lo que podría implicar también el uso de la violencia.

En el Estado postmoderno, la violencia física como medio de control o estrategia de opresión de los conflictos sociales, tiene un alto rechazo. También se desprecia el uso de la violencia física como 
estrategia de eliminación del contrario. Sin embargo, la violencia ejercida por el Estado en épocas anteriores se consideraba como una acción no solo lógica y aceptable, sino también como un espectáculo abierto que era disfrutado por los dominados 23 .

Por otro lado, la sociedad civil es un espacio en donde coexisten múltiples grupos con intereses, valores, culturas, etc., que no sólo pueden ser distintos unos de otros, sino que pueden ser contrarios y por ende, susceptibles al conflicto, entonces, ¿qué papel le cabe al Estado en esta materia?

Uno de los principios básicos de todo Estado de derecho, es mantener una convivencia social que permita tanto a los individuos como a los grupos su desarrollo. Sin embargo, el conflicto es parte de esta convivencia social, y se establecen mecanismos jurídicos de mediación para solucionarlo. Empero, cuando los grupos no respetan las soluciones jurídicas o el objeto de disputa implica condicionar su sistema de vida, entonces el Estado debe, por medio del órgano Ejecutivo, involucrase como un tercero en el conflicto llevándolo al campo de la solución política, de modo de evitar la crisis y con ello la posibilidad de la violencia.

Como corolario, se debe advertir que el fenómeno de las redes virtuales tiene un efecto multiplicador y acelerante de los conflictos. Los grupos de interés y especialmente los movimientos sociales, mediante el uso de redes sociales, logran la concurrencia de adeptos y, por ende, obtienen mayor poder para que sus planteamientos tengan más fuerza. Soengas ${ }^{24}$, en su investigación sobre el papel de Internet y de las redes sociales en las revueltas árabes, concluye que "la tecnología puede actuar como un arma de acción asociada a un fenómeno reivindicativo local y conseguir que adquiera una dimensión global". En consecuencia, los conflictos sociales adquieren una dinámica cuyo escalonamiento es más veloz y masivo, pudiendo converger múltiples casos de conflictos que pueden sobresaturar la capacidad de respuesta del Estado.

El estudio político implica el análisis del proceso de toma de decisiones legítimas y la respuesta al conflicto en torno a esas decisiones ${ }^{25}$. En este marco y teniendo presente todo lo anterior, se ha procedido a desarrollar un esquema conceptual denominado "ciclo de la (des) construcción" que pretende entregar una mirada teórica sobre los procesos y los mecanismos que se encuentran tanto en forma subyacente, como explicita, en la construcción del rol del Estado, cualquiera sea la materia. Es importante advertir que el concepto de "(des)construcción" utilizado no tiene el mismo sentido epistemológico de Derrida y tampoco se lo debe confundir con su complejo concepto de "decontrucción", el cual se podría resumir, a riesgo de ser simplista, que todo lo presente es un resultado de un sistema diferencias anteriores produciendo una infraestructura o "arquetipos-síntesis"26. Acá el concepto de (des)construcción tiene un reflejo temporal del ciclo de vida del diseño políticonormativo de una norma, que, transcurrido determinado tiempo, puede sufrir el reemplazo por una nueva. Este fenómeno ocurriría simultáneamente, es decir, se construye y destruye a la vez, pudiendo tener un alcance parcial o total, por ejemplo, la modificación de una parte una ley o su reemplazo total. Sin embargo, también puede ocurrir que solo exista una construcción sin destrucción y viceversa.

Aclarado lo anterior, el supuesto general del esquema teórico se ve reflejado gráficamente en la figura 1, la que se basa en tres fases de temporalidad representados por: Fase 1, Declaración y ejecución

23 Byung Chul Han, Sobre el poder, Ed. Heder, España, 2016, 11-44

24 Xosé Soengas-Pérez, The Role of the Internet and Social Networks in the Arab Uprisings An Alternative to Official Press Censorship Comunicar, 41, España, 2013, 147-155.

25 Reiner Bauböck, Normative Political Theory and Empirical Research in Della Porta, D \& M. Keating, Approaches and Methodologies in the Social Sciences: A Pluralist Perspective, Cambridge University, New York, 2008, 316-322

26 Ramiro Borges, La deconstrucción en Jacques Derrida: Qué es y qué no es como estrategia. Universitas PhilosoPhica Nº0, 2013, 177204, disponible en https://revistas.javeriana.edu.co/index.php/vniphilosophica/article/view/10788; Darin McNabb, Omne Symbolum de Symbolo: Las Huellas de Peirce que Derrida no rastreó. Open Insight, vol. III, no. 4, 2012, 93-111, disponible en www.unav.es/gep/OpenInsightDarinMcNabb.pdf; Luis Aragón, "La dimensión política de la deconstrucción". Revista Internacional de Filosofía, no 54, 2011, 45-59. 
del rol; Fase 2, Cuestionamiento del rol; y Fase 3, El nuevo rol. Todos estos periodos de tiempo están marcados por paradigmas sociales, culturales, económicos y la ideología sociopolítica predominante las cuales otorgan un contexto de comprensión en la construcción del rol del Estado. A medida que pasa el tiempo, se va generando un ciclo dialéctico en que el rol avanza y se transforma, dando origen a un nuevo paradigma. Para la generación de un determinado rol estatal, se desarrolla el siguiente análisis secuencial:

a) En la Fase 1, "Declaración y ejecución del rol”, los agentes políticos, grupos de interés, movimientos sociales, interactúan conflictivamente entre sí, para determinar el rol del Estado con respecto a una determinada materia u objeto a ser regulado teniendo presente su poder, valores, ideología e intereses. El objetivo de cada incúmbete es tratar de influir en el órgano Ejecutivo y el Legislativo del Estado en el proceso del diseño político-normativo en que se expresará jurídicamente el rol del Estado en el objeto en cuestión. Cabe destacar que los agentes internacionales, también podrán ser parte de la disputa, pero normalmente en forma indirecta mediante la alianza con algunos de los agentes nacionales.

Construida la norma y sancionada como ley, en ella se establece el rol formal del Estado, el cual es puesto en marcha por el órgano Ejecutivo. En el proceso temporal de ejecución de la norma se pueden generar dos escenarios: 1) un funcionamiento armónico del diseño, es decir, su aplicación en la realidad no genera resistencias y si las produce son muy bajas; 2) Una operación discordante, es decir su aplicación provoca conflictos en la sociedad causado por malos procedimientos, falta de presupuesto, el diseño político-normativo ya no se ajusta a la realidad emergente, de tal manera que hay un desacople político-normativo por el cambio de época.

b) Producto de lo anterior, Fase 2 "Cuestionamiento del rol", si el diseño políticonormativo no funciona adecuadamente se generan altos niveles de pugnas o crisis, en un cuadro marcado por la conflictividad social, cuyo objetivo será generar presión para que la ley o su aplicación cambie. En esta dirección, quienes detenten el poder podrán usar mecanismos opresivos para controlar al grupo o podrán también generar instancias que permitan una solución al problema de la fricción del diseño, inyectando, por ejemplo, mayores recursos o la modificación de procedimientos para volver hacia una condición de funcionamiento armonioso del diseño. En el caso contrario, la intensidad del conflicto puede generar crisis que a su vez gatillarán la necesidad de cambios en el rol estatal.

Lo que caracteriza esta etapa del ciclo, es la emergencia de nuevas temáticas y demandas propias del nuevo contexto del período que pueden ser contradictorios con la época anterior, por ejemplo, el surgimiento de nuevos derechos. Si estas demandas no son gestionadas adecuadamente, se pueden generar conflictos sociales que impulsarán a generar un nuevo rol estatal.

c) Los procesos sociales de conflictividad social no son instantáneos y tendrán una evolución dentro de la Fase 3 "El nuevo rol", es una etapa de cambio, por ende, de conflictividad, cuya intensidad estará determinada por mecanismos de gobernanza desarrollados. La expresión de esta conflictividad se concretará por medio de la opinión pública, los multimedios, movilizaciones y redes virtuales. Estas demandas serán apropiadas por las diversas organizaciones de la sociedad civil, quienes, constituidas en grupos de interés, comenzarán a exigir cambios en el diseño político-normativo (desconstrucción) o la formulación de uno nuevo, en donde también entrarán a jugar los partidos políticos, el órgano ejecutivo y el legislativo, quienes generarán un nuevo diseño político normativo o cambiarán su diseño, según sea el caso. Creándose un nuevo o modificado rol estatal, en consecuencia, un nuevo ciclo.

Cabe destacar que siendo el Estado un actor recurrente en el conflicto social, éste tendrá una fuerza normalmente superior al resto de los actores, por lo que podrá resistir un largo periodo un determinado conflicto. Esta resistencia podría ser utilizada como un instrumento por parte de una elite dominante para conservar cuotas de poder o salvaguardar intereses económicos o valóricos. 
La duración de los ciclos dependerá del objeto que trate el rol estatal definir o redefinir, y dado que el Estado tiene múltiples roles no es de extrañar que en una misma época surjan variadas temáticas conflictivas cuestionando el rol del Estado. La duración del conflicto también dependerá de la fuerza de los otros actores involucrados, es decir, sus recursos, alianzas, influencia, poder y por sobre todo el significado que tiene el objeto en negociación o disputa.

El desafío estará en el cómo y la capacidad de gestionar los conflictos, especialmente cuando es el poder Ejecutivo quien pone en marcha el diseño político-normativo. Se debe reiterar que dicho órgano estatal, tratará de que el conflicto pueda ser manejado "intra-muro" a fin de no perder poder y control sobre este. En el diseño del rol estatal, en un régimen democrático, intervendrán la mayor cantidad de actores, por tanto, el rol del Estado será el resultado de un consenso en el que predominará teóricamente la posición de la mayoría con la incorporación de algunos elementos negociados de las minorías.

Figura 1: Ciclo de la (des)construcción del rol del Estado

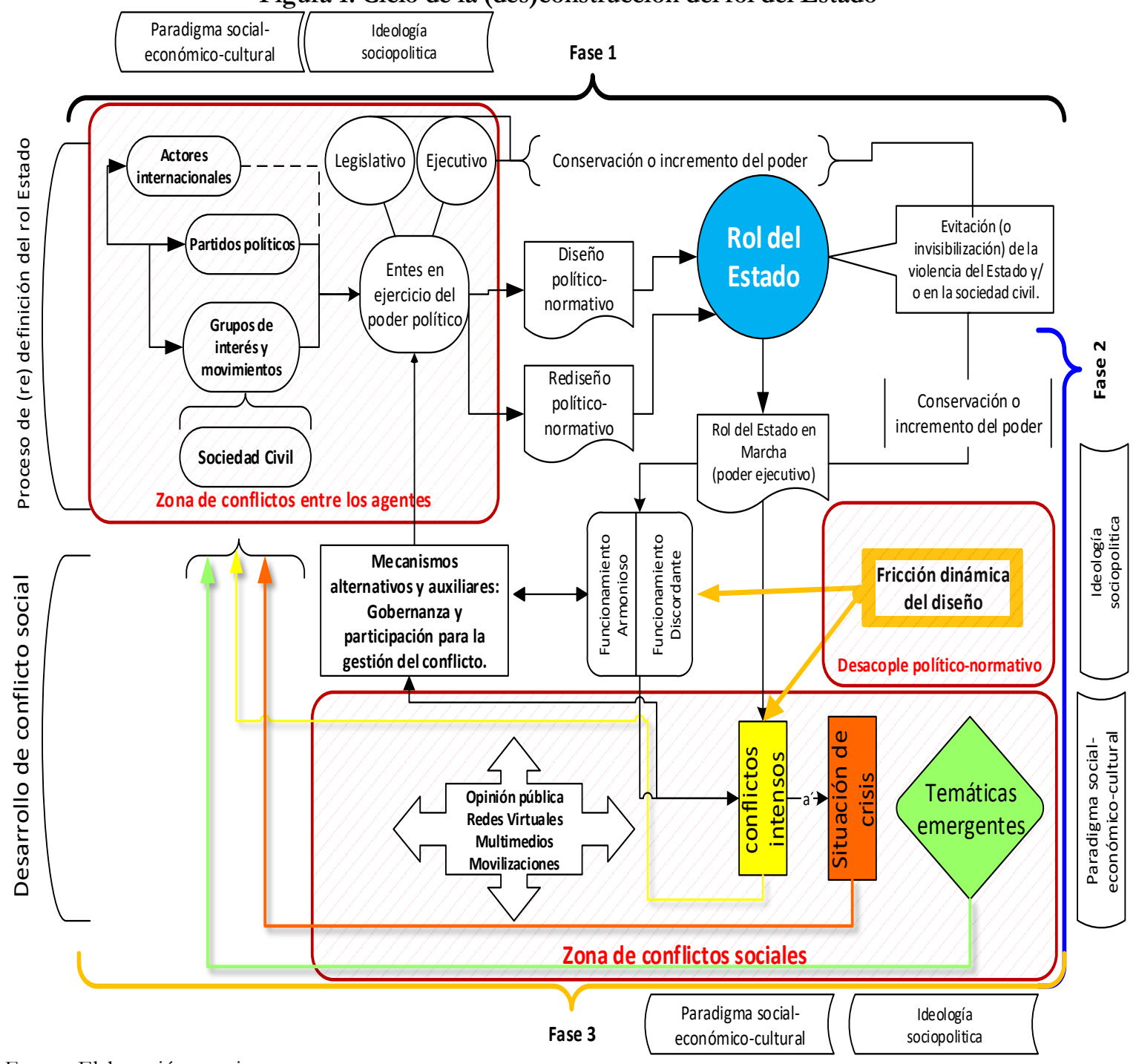

Fuente: Elaboración propia 
Este proceso no estará exento de los grupos de interés que realizarán la correspondiente presión, especialmente cuando sientan que es una oportunidad para ganar, mantener o salvaguardar su visión. También la opinión pública tanto nacional e internacional, tendrá un efecto en el diseño, especialmente cuando el tema sea una preocupación generalizada o viralizada por las redes sociales.

Es importante mencionar que el diseño, finalmente, se expresa en forma tangible mediante la construcción de una ley que emana de un acuerdo político. De allí que se habla de un diseño políticonormativo y dependiendo del régimen, este diseño podrá ser abierto, restringido o cerrado.

Se puede sostener que un diseño abierto ocurre en el ámbito de un régimen democrático en que el ejecutivo y el legislativo negocian. Dicho contexto permite espacios de opinión e influencia de los grupos de interés y la sociedad civil en general.

En tanto que el diseño restringido, propio de regímenes autoritarios, se caracteriza por cuanto los acuerdos y la aprobación del diseño político-normativo se encuentran en un solo órgano del Estado, es decir, el Ejecutivo, dejando amplios espacios de influencia para los grupos de interés simpatizantes con el gobierno, y un limitado margen de opinión para aquellos que son contrarios.

Un diseño cerrado predomina solo una posición política, los grupos de interés son equivalentes al régimen, no existe oposición, es decir, son diseños políticos-normativos totalitarios o dictatoriales.

Se debe relevar que, en un régimen democrático, los diseños del rol estatal en diversas materias tienen una mayor posibilidad de que sean influenciados por los grupos de interés y los movimientos sociales. Esto no garantizaría un diseño basado en el principio de equidad, pero da una posibilidad a la construcción de un consenso o al menos consideraciones de las minorías.

En cambio, un régimen autoritario o uno de carácter dictatorial seria influenciado solo por el grupo de interés que lo apoye y le sea fiel. Por lo tanto, el diseño resultante no afectará al grupo de interés privilegiado, más bien le beneficiará en detrimento del resto.

Otro factor que se debe considerar es la vigencia y el cambio de los diseños políticonormativos. La construcción política-normativa desarrollada por quienes ostentan el poder político implica regular un sector, actividades o patrones de conducta de la sociedad, para un momento del paradigma social-económico-cultural determinado. Sin embargo, dada la naturaleza dinámica de la sociedad, de los modos de producción, de los cambios en el patrón de los valores, los derechos, la tecnología y la cultura, entre otros, el diseño político-normativo vigente entra en un proceso de entropía producto del desajuste con las nuevas necesidades o demandas emergentes. Sin embargo, cabe preguntarse: ¿cómo se origina el cambio del diseño o la incorporación de nuevos diseños?, ¿qué procesos subyacen en la construcción o desconstrucción del rol estatal en una determinada materia?, ¿cómo se expresan las resistencias o las defensas cuando el diseño político-normativo se encuentra operando?

Los viejos diseños del aparato estatal que se mantienen en operación se verán afectados cuando ya no respondan adecuadamente a las demandas, necesidades, valores, intereses actuales o porque una comunidad o parte de la población acuse inequidad en su aplicación, es decir, emergen las fricciones.

Por lo tanto, de esta situación emergerán conflictos sociales desde la sociedad civil, en donde grupos y movimientos presionarán directa o indirectamente para que la materia regulada sea rediseñada o simplemente eliminada.

Sin embargo, los cambios serán resistidos por aquellos grupos de interés que se han visto previamente beneficiados del diseño en cuestión. En consecuencia, se presentarán disputas también en el ámbito de la sociedad civil.

El cambio en el diseño tendrá varias barreras burocráticas que enfrentar, especialmente si existen grupos de interés que presenten una alta influencia y control en las esferas del poder estatal. En este trance, los conflictos entran en ciclos que van variando en intensidad y duración, pero a largo plazo pueden provocar serios problemas de gobernabilidad en una determinada materia. 
Propuesto el modelo y en concordancia con la pretensión de esta investigación, en el siguiente apartado se procederá a aplicar el "Ciclo de la (des) construcción del rol del Estado" en el SEIA, con el fin de comprender el derrotero de su diseño político-normativo contenido en la ley 19.300.

\section{4.- Caso: La (des)construcción de rol ambiental chileno en SEIA.}

Como se ha indicado en los párrafos precedentes, el incremento del conflicto socioambiental es un fenómeno reciente y acelerado, lo cual ha generado un impacto en el quehacer del Estado chileno siendo una parte importante en la agenda pública por las implicancias sociales, políticas, ambientales y económicas que conlleva.

A pesar de las reformas que ha sufrido la institucionalidad ambiental, los conflictos no encuentran canales de solución en el poder ejecutivo, todo lo contrario, es en las instancias judiciales donde se tratan de resolver las disputas. Entonces cabe preguntarse: ¿Qué fricciones del diseño político-normativo impide al Estado, en especial al poder ejecutivo, abordar los conflictos?; ¿por qué en menos de 8 años de existencia de una nueva institucionalidad ambiental, se requiere de una nueva reforma al SEIA?

A continuación, se intentará dar respuestas a estas interrogantes que refuerzan el propósito original de esta investigación por medio del ciclo de la (des) construcción del rol del Estado con respecto al medio ambiente general y el SEIA en particular:

Fase 1 (Génesis del rol estatal): Emerge a partir de los años 80. Está marcado por incipientes señales desde el contexto internacional por lograr acuerdos para un desarrollo económicamente sustentable, controlar la contaminación, frenar la sobreexplotación de los recursos naturales y abordar los problemas de contaminación asociados al crecimiento económico de cada país. Se destaca en este periodo la Unión Internacional por la Conservación de la Naturaliza, UICN, que en 1980 puso en la agenda internacional la necesidad de una tipología de desarrollo que abordara los problemas ambientales que han emergido por los modelos económicos, considerando a su vez una relación armónica entre el desarrollo humano y la conservación de la naturaleza. En 1983 se crea la Comisión Mundial sobre Medio Ambiente y Desarrollo, dependiente de la ONU cuyo objetivo fue proponer una serie de medidas que permitiera a las naciones generar soluciones ante el creciente deterioro del planeta. Esta Comisión fue conocida por generar el informe nuestro Futuro Común (1985) o Informe Brundtland, en donde surge una alternativa y el concepto de "Desarrollo Sustentable"27.

Es así como, en plena dictadura, por decreto supremo $\mathrm{N}^{\circ} 271^{28}$, se creó la Comisión Interministerial de Ecología (1984), cuya finalidad era asesorar al presidente en materias de protección ambiental y recursos naturales, además de proponer la creación de un Organismo o Sistema Nacional del Medio Ambiente para formulación, unificación, desarrollo e implementación de políticas que el gobierno de ese entonces estimara conveniente para la protección del medio ambiente y el racional uso de los recursos naturales renovables.

Dicha comisión, estaba compuesta por los ministros: del Interior, quien la presidia; Defensa Nacional; Agricultura; Bienes Nacionales; Salud; y Ministro Director de la Oficina de Planificación Nacional. Cabe resaltar que el único civil que conformó la comisión fue el ministro del interior, todos los demás tenían rango de generales de las diversas ramas castrenses. Contaba además con una secretaria técnica ad honorem y 15 asesores de diversas temáticas como salud, ecología, forestal, entre otros.

27 Pablo Camus y Ernst Hajek, Historia Ambiental de Chile, Ed. Andros, Santiago, 1998, 11-16

${ }^{28}$ Véase en sitio web ley Chile, https://www.leychile.cl/Navegar?idNorma=15055, Revisado 5 de enero de 2019. 
Lo anterior permitió también orientar al gobierno dictatorial en la aplicación del artículo 19 número 8 de la Constitución. Dado un régimen dictatorial, el diseño político-normativo no tuvo un proceso de conflicto o de participación de la sociedad civil o de los grupos de interés en la construcción de dicho rol.

Fase 2 (E1 rol en cuestionamiento): se dio en el contexto del retorno a la democracia, momento en que se rearticularon los poderes del Estado para volver a la división clásica de los mismos. Con relación a la temática ambiental, la evaluación de la gestión ambiental de la dictadura fue que había dejado una deuda ambiental que era significativa de corregir dado el acento que se puso en el crecimiento y la disminución del Estado ${ }^{29}$, propio del modelo neoliberal impuesto.

En el año 1990, el nuevo gobierno democrático creó la Comisión Nacional del Medio Ambiente, CONAMA, (DS No 240/90) cuya función era eminentemente asesora de nivel presidencial, encargada del estudio, propuesta, análisis y evaluación de todas aquellas materias relacionadas con la protección y conservación del Medio Ambiente. Sin embargo, cuatro años después, mediante la dictación de la Ley $\mathrm{N}^{\mathrm{O}} 19.300^{30}$, se consolidó legalmente CONAMA como modelo transversal para garantizar la coordinación del sector público en la temática ambiental; determinar las competencias de los servicios y ministerios en la materia; la descentralización mediante la creación de las Comisiones Regionales del Medio Ambiente; y, en especial, administrar el sistema de evaluación de impacto ambiental.

La puesta en marcha del modelo coordinador de CONAMA, en los catorce años siguientes a su creación, comenzó a sufrir un proceso propio de la fricción del diseño generándose un desacople político-normativo, el que se manifestó del siguiente modo: a) un creciente aumento de los conflictos y movimientos socioambientales y su judicialización; b) dificultades de coordinación transversal en una administración pública verticalista; c) preminencia de decisiones con criterios políticos por sobre los técnicos; d) asimetrías de información entre los afectados por un proyecto de inversión productiva y los titulares que presentan los estudios de impacto ambiental; e) centralismo en la toma de decisión final en la aprobación de los proyectos; f) fiscalización insuficiente; g) cuestionamiento al proceso de participación ciudadana; h) gestión ambiental local precaria; e i) normativa ambiental sectorial era definida por los actores del sector económico afectado ${ }^{31}$. Es relevante recordar que la OCDE también en su informe del 2005 presentó críticas y sugerencias para mejorar la institucionalidad ambiental.

Fase 3 (E1 nuevo rol): En el año 2008, se procede al rediseño de la institucionalidad ambiental mediante el envío del mensaje presidencial, que contenía el proyecto de ley, para ser discutido en el parlamento. Durante el dialogo de redefinición del rol del Estado, tanto los miembros de la sociedad civil como del ámbito privado fueron representados por grupos de interés altamente organizados. En las audiencias se registró la presencia de seis representantes gremiales del sector privado; seis representantes de organizaciones no gubernamentales (ONGs) ambientales y gremios profesionales; cuatro centros de investigación de derecha, izquierda y centro; una universidad y dos asociaciones de

\footnotetext{
${ }^{29}$ Rafael Asenjo, Institucionalidad Pública y Gestión Ambiental en Chile, Rev. Expansiva, Foco 21, Chile, 2006, 1-19 30 Véase en sitio web ley Chile, https://www.leychile.cl/Navegar?idNorma=30667, revisado 5 de enero de 2019.

31 Asenjo, Op. Cit.; Jonathan Barton et al, El nuevo diseño de la institucionalidad ambiental en Chile, Propuestas para Chile, Centro de Políticas Públicas, Pontificia Universidad Católica, Santiago, 2007, 137-178; Camila Boettiger, Nueva institucionalidad ambiental, Actualidad Jurídica (UDD), Año XI, No 22, Chile, 2010, 429-454; Matías Guiloff, El dilema del artículo $19 n^{\circ} 8$ inciso 2, Revista de Derecho, Universidad Católica del Norte, Año 18 - No 1, Chile, 2011, 147-169; TERRAM, Análisis, desafíos y críticas a la nueva institucionalidad ambiental, XIV congreso CECADES, Universidad de Playa Ancha, Chile, 2011; Khaterine Lobos, Análisis de la nueva institucionalidad ambiental desde la reforma a la ley 19.300. Tesina. Universidad Católica de la Santísima Concepción, 2015.
} 
funcionarios ${ }^{32}$. En este proceso, el conflicto no estuvo ausente pues cada grupo pretendía establecer el nuevo rol que debería tener el Estado. Tanto el ejecutivo como el legislativo utilizaron algunos mecanismos propios de la gobernanza, especialmente los vinculados con la información, transparencia, receptividad y participación. En concreto, hubo audiencias, reuniones, charlas, debates, simposios y opinión por medio de redes virtuales, esto con el fin de gestionar el conflicto en la construcción del nuevo rol estatal, por lo tanto, era necesario que se recogieran las propuestas y críticas de cada grupo de interés.

Dado lo complicado y las diversas variables sociales, económicas, ideológicas, culturales, ambientales, valóricas del proyecto de ley, éste recibió una gran cantidad de indicaciones presentadas por los parlamentarios quienes canalizaron las observaciones de los grupos de interés. Sin embargo, el entonces presidente de la Comisión de Medio Ambiente y Bienes Nacionales del Senado 33 , propició un protocolo de acuerdo de 11 puntos, con el propósito de zanjar rápidamente la discusión para mantener el "conflicto intra-muro", lo que significó el retroceso de acuerdos e indicaciones realizados por la Cámara de Diputados, entre ellos se destacan: a) No fue considerado el concepto de contaminación que tenía definiciones más avanzadas, se mantuvo la premisa que es contaminación siempre y cuando lo determinará la norma técnica; b) se descartó la reformulación del concepto de participación ciudadana que incluía un carácter informativo, consultivo o resolutivo en las evaluaciones ambientales estratégicas; c) se eliminó la capacidad de los servicios públicos para pronunciarse sobre aspectos no normados en la evaluación de un estudio de impacto ambiental; y d) se excluyó la posibilidad que los proyectos se ajustaran a las políticas, planes y programas de desarrollo regional, así como a los planes de desarrollo comunal ${ }^{34}$. Desde el punto de vista del conflicto en la construcción del rol estatal, tal como lo expresa Grinberg,

La problemática ambiental es monopolizada por “expertos", condicionada por políticos, y deformada por la acción de grupos de presión o lobbies al servicio de corporaciones transnacionales nada interesadas en la alteración de las reglas del juego fijadas por los megapoderes que rigen la vida contemporánea" 35 .

Lo anterior es totalmente coherente con lo que indica Stigler ${ }^{36}$, por cuanto en las lógicas de la industria también existe la posibilidad de usar el Estado y su capacidad de coerción para preservar o mejorar su propósito, siendo clave el proceso regulatorio del Estado y los intereses económicos. En un contexto en el cual existe condiciones estructurales que facilitan y hacen eficaz la labor de los grupos de presión, dado el escaso conocimiento e información que maneja la ciudadanía en general de los asuntos públicos ${ }^{37}$.

Se debe destacar que la decisión del presidente de la comisión con poder de veto institucional ${ }^{38}$, dejó fuera aspectos relativos al apoyo técnico para que las comunidades puedan disminuir la asimetría con la que se enfrentan ante complejos estudios de impacto ambiental, la regulación de la "compra de conciencia" o negociación incompatible que desarrollan las empresas en su pretensión de instalarse en

32 Ver párrafo segundo del Informe de la Comisión de Medio Ambiente y Bienes Nacionales, recaído en el proyecto de ley, en segundo trámite constitucional, que crea el Ministerio, el Servicio de Evaluación Ambiental y la Superintendencia del Medio Ambiente. BOLETÍN No 5947-1 (2009).

33 Pablo Longueira, fue senador de Unión Demócrata Independiente entre el 2006-2011.

34 Ver segundo informe de la Comisión de Medio Ambiente y Bienes Nacionales del Senado, noviembre 2009.

35 Miguel Grinberg, Ecofalacias, Galerna. Argentina, 1999, 12-20.

${ }^{36}$ Geoger Stigler, La teoría de la regulación económica, CIERIC-España, Revista de Economía Pública, Social y Cooperativa, $N^{\circ}$ Extraorinario, España, 1990, 81-115.

37 Mancur Olson, La lógica de la acción colectiva, Diez textos Clásicos de Ciencia Política, Ariel, Barcelona,1986, 203-220.

38 Veto en el sentido que le da George Tsebelis, en su obra Jugadores con veto. Cómo funcionan las instituciones politicas, Fondo de Cultura Económica, México, 2006.ver paginas 27-49 
un determinado territorio; unidad de resolución de conflictos socioambientales y el reconocimiento legal del principio precautorio, entre otros ${ }^{39}$.

En concreto, el acuerdo entre el poder legislativo y el ejecutivo implicó una sinergia de fuerzas que permitió la construcción del nuevo diseño que excluyó las consideraciones de los grupos de interés que aspiraban a un rol del Estado mucho más fuerte, fiscalizador y con participación resolutiva en los Estudios de Impacto Ambiental. Por otro lado, las instituciones ambientales creadas recientemente otorgaron una mayor jerarquía a los temas ambientales.

Con todo, el nuevo modelo sigue sosteniendo elementos claves que habían sido criticados previamente en momentos o fases iniciales del diseño del rol en cuestión, y puesto en evidencia por las organizaciones ambientales ciudadanas y la academia. Obedeciendo a una logia. Es así como después de ocho años de puesta en marcha, ese rol comenzó a sufrir fricciones dinámicas del diseño, lo que se refleja en algunos síntomas:

a) En una encuesta realizada el 2014 a 138 empresas, el 91\% consideró que el nuevo reglamento del SEIA no era suficiente para minimizar la judicialización de los proyectos ${ }^{40}$.

b) El año 2015, se creó la Comisión Asesora Presidencial para la Reforma del SEIA41, cuyo objetivo fue desarrollar propuestas para disminuir los conflictos socioambientales y corregir deficiencias en el funcionamiento del SEA. El órgano en su primer año estuvo compuesto por cuatro autoridades de gobierno, trece del sector privado, tres ONGs vinculadas a los temas ambientales y tres miembros pertenecientes a universidades o centro de estudios.

Dada la asimetría de los actores, dos ONGs renunciaron a la comisión ${ }^{42}$, posteriormente, lideraron y crearon la Comisión Sindical Cívico Parlamentaria (CSCP) para la Reforma del SEIA ${ }^{43}$, una instancia paralela compuesta por dieciocho ONGs, dos federaciones de trabajadores, seis diputados y dos senadores. Para la CSCP, existen dos ejes estructurales que requieren de un cambio radical. Uno de ellos es la instancia de participación ciudadana la cual resulta precaria para la expresión de las preocupaciones e intereses de la comunidad, como también en la necesidad de democratización de las decisiones en materia ambiental y territorial. El segundo eje atañe a los conflictos socioambientales que surgen entre titulares de los proyectos de inversión productiva y comunidades, por cuanto el Estado se presenta ausente y si existe algún involucramiento de este, el ejecutivo prioriza los intereses del inversionista por sobre los intereses locales, "bajo la lógica de que es prioritariamente la iniciativa privada la que impulsa el desarrollo" 44 .

c) Otro factor que fue objeto de críticas es el escaso presupuesto que destina el Estado para fiscalizar incumplimientos en materia ambiental. La institucionalidad ambiental posee una de las menores asignaciones presupuestarias del aparato público dependiente del ejecutivo ${ }^{45}$, situación que

39 Ver en TERRAM, Reforma a la institucionalidad ambiental: El análisis y la reflexión necesarios, 2009, disponible en https://www.terram.cl/images/minutas/minuta_reforma_ambiental_dic09_terram.pdf, revisado el 5 de enero de 2019

40 Price Waterhouse Consulting, Judicialización de proyectos y conflictos indigenas: ¿Cómo evitarlos?, disponible en http://www.acera.cl/wp-content/uploads/2014/03/Judicializaci $\%$ C3\%B3n-de-Proyectos-y-Conflictos-Ind $\%$ C3\%ADgenasV5.pdf, revisado el 5 de enero de 2019

41 Véase en https://www.gob.cl/noticias/mandataria-crea-la-comision-asesora-presidencial-para-el-estudio-de-un-nuevosistema-de-evaluacion-de-impacto-ambiental-seia/, revisado 5 de enero de 2019.

42 Véase en https://www.terram.cl/2015/12/ongs-ambientales-renuncian-a-comision-asesora-presidencial-para-reforma-delseia/, revisado el 5 de enero de 2019.

43 El Ciudadano, "Sindicatos, parlamentarios y organizaciones crean comisión paralela para reforma al SEIA", https://www.elciudadano.cl/organizacion-social/parlamentarios-organizaciones-crean-comision-paralela-para-reforma-alseia/09/28/, revisado el 5 de enero de 2019.

${ }^{44}$ Comisión Sindical Cívico Parlamentaria, Informe de la Comisión Sindical Cívico Parlamentaria para la Reforma del SEIA, disponible en http:// wnw.fima.cl/wordpress/2016/08/10/infome-de-la-comision-sindical-civico-parlamentaria-para-la-reforma-del-seial, revisado el 5 de enero de 2019. P. 4

45 Véase en http://www.dipres.gob.cl/597/articles-172496_doc_pdf.pdf, revisado el 5 de enero de 2019. 
impide desarrollar en plenitud sus funciones. Una consecuencia del bajo presupuesto es que, por ejemplo, sólo un 9,5\% de las 15.000 Resoluciones de Calificación Ambiental (RCA), aprobadas han podido ser fiscalizadas desde 2014 hasta $2018^{46}$, lo que claramente es una señal de fricción del diseño político-normativo con la realidad, por cuanto se genera en la sociedad una insatisfacción de los servicios otorgado por el Estado en términos de supervigilar el cumplimiento de la normativa ambiental por parte de las empresas, generándose una potencial fuente de disputas.

En suma, lo paradojal es que, en un corto periodo de implementación de la nueva institucionalidad ambiental, ésta ya es cuestionada especialmente, en lo concerniente a su actuación en los proyectos de inversión y los conflictos socioambientales.

\section{5.- Conclusiones}

El conflicto es un proceso de oposición activa entre dos o más actores que, según su fuerza, buscarán imponer su dominio en un objeto determinado. La duración del mismo dependerá del valor subjetivo que le asignen los involucrados a la cosa en pleito y los mecanismos existentes para su gestión.

El conflicto social se encuentra presente en la dinámica transformativa del Estado, el cual está sometido a una tensión permanente. En este contexto, la utilización del poder será en función a la importancia que representa el objeto y dependiendo de la fuerza del actor, éste podrá imponer su visión de cómo debe ser regulado y gestionado en el nivel micro, es decir, en el tejido social.

Cruzando los componentes el desarrollo teórico del rol del Estado de Oszlak con el diseño político-normativo, su operación se encontraría en el nivel Meso y el diseño se encontraría en el nivel Macro. Ambos niveles fuertemente influenciados por factores de legitimidad y valoración que emerge desde el nivel micro y según sea el caso, intervendrán en la escena los actores internacionales.

Aunque suene obvio, el diseño político-normativo estaría condicionado por las ideologías, los valores, intereses y los pactos sociales que se encuentran en el nivel macro y que se van concretando en el nivel meso a través de diversos instrumentos de gestión, donde también el diseño en el momento de su ejecución puede ser alterado por factores internos o externos al aparato estatal, y que finalmente terminan con la entrega de servicios que pueden o no satisfacer a la sociedad civil.

El modelo propuesto sobre el ciclo de la (des)construcción del rol del Estado permite comprender y explicar cómo, en términos estructurales, se construyen los roles del Estado, basado en una lógica dialéctica. El ciclo entrega la posibilidad de explicar los procesos y los mecanismos que se encuentran tanto en forma subyacente como explícita en la conformación del rol. En este contexto, surge las propuestas conceptuales: "fricción del diseño político-normativo" y "desacople políticonormativo" que ayudan a comprender la entropía del rol.

El neoliberalismo busca un Estado con roles mínimos como, por ejemplo, proveer seguridad pública y protección de la propiedad de las personas, en donde el mercado se regula así mismo, con condiciones laborales con bajo nivel de protección y flexibilización de los contratos. Los servicios de salud, educación y otros son entregados al mercado y se provee servicios básicos asistencialistas para la población más pobre. Sin embargo, es importante indicar que según Maillet ${ }^{47}$, el neoliberalismo tiene sus propias variantes: a) Ortodoxo, donde el Estado juega un papel mínimo en el mercado y la sociedad; b) Regulado, el Estado juega un papel interventor mínimo mediante las leyes para proteger o promover la competencia y planificación económica; c) Emulador, el Estado frente a fallas del mercado y mediante sus mecanismos, genera condiciones que permita el desarrollo de la competencia para la

46 El cálculo del porcentaje se ha basado en los datos provistos de "Memoria de Gestión 2014-2018" de la Superintendencia del Medio Ambiente (SMA), Chile, 2018, 9-32. Disponible en https://portal.sma.gob.cl/index.php/publicaciones/

47 Antoine Maillet, Variedades de neoliberalismo. Innovación conceptual para el análisis del rol del Estado en los mercados. Revista de Estudios Políticos Núm. 169, 2015, 9-136, Disponible en http://dx.doi.org/10.18042/cepc/rep.169.04 
provisión de un determinado bien o servicio; y d) Mixto, el rol que asume el Estado en esta variante del neoliberalismo es la provisión de un bien o servicio en el marco de las reglas del mercado.

En este sentido, el aporte teórico de Maillet, puede responder al sostenimiento del modelo económico de la dictadura, en donde se transita desde un neoliberalismo ortodoxo hacia un neoliberalismo regulado desarrollado en democracia, lógica que permea tanto en el diseño políticonormativo de CONAMA como en la nueva institucionalidad ambiental que la reemplaza. En forma específica esto se puede observar en el sistema de evaluación de impacto ambiental y las instancias auxiliares a este, como el Consejo de Ministros en donde prevalece el criterio de que las inversiones no sean frenadas sino reguladas, esto por sobre las condiciones de vida de las localidades y el medio ambiente que la sustenta.

La (des)construcción dialéctica del rol ambiental del Estado chileno tuvo tres momentos: el primero reflejado en una dominación autoritaria donde la dictadura incorpora un enfoque ambiental higienista. El segundo momento, se instala un régimen democrático, en que se crea una institucionalidad ambiental de baja jerarquía. Por último, en la tercera versión del diseño, se puede observar un constructo a nivel ministerial, el que cuenta con la opinión de los distintos actores, pero prevalece una corriente neoliberal con seudo-satisfactores que cede algunos aspectos normativos hacia los otros grupos de interés. Sin embargo, el modelo vuelve, en un corto plazo, a generar fricciones y el correspondiente desacople.

Desde el punto de vista de la teoría conflictualista liberal, en la conformación del rol ambiental, nos encontramos también con el factor del poder, en que el diseño permite que el ejecutivo pueda tener la capacidad de dirigir o impedir las acciones actuales o futuras de los grupos ambientales, donde la vinculación entre el ejecutivo y los actores de este juego es asimétrica, en que el sector privado tiene a su favor un Estado con vocación neoliberal, con mecanismos que le permiten un control de las dinámicas productivas, utilizando la burocracia o las instancias políticas, en detrimento de otros grupos de la sociedad civil los que sin embargo, podrían reaccionar mediante la judicialización o la generación de movimientos sociales.

\section{Bibliografía citada}

Asenjo, Rafael. Institucionalidad Pública y Gestión Ambiental en Chile, Rev. Expansiva, Foco 21, Chile, 2006. Barton, Jonathan et al. El nuevo diseño de la institucionalidad ambiental en Chile, Propuestas para Chile, Centro de Políticas Públicas, Pontificia Universidad Católica, Santiago, 2007, 137-178.

Bauböck, Reiner. Normative Political Theory and Empirical Research in Della Porta, D \& M. Keating, Approaches and Methodologies in the Social Sciences: A Pluralist Perspective, Cambridge University, New York, 2008.

Boettiger, Camila. Nueva institucionalidad ambiental, Actualidad Jurídica (UDD), Año XI, No 22, Chile, 2010, 429-454.

Bragado, Ignacio. Física General, Ed. Universidad de Valladolid, España, 2004.

Camus, Pablo y Hajek, Ernst. Historia Ambiental de Chile, Ed. Andros, Santiago, 1998.

Contreras, Arturo. Los Estudios del Conflicto: una necesidad en la era post moderna. Revista Política y Estrategia $\mathrm{N}^{\circ}$ 91, Chile, 2003, 9-34.

Coser, Lewis. Nuevos Aportes a la Teoría del Conflicto Social, Ed. Amorrurtu, Argentina, 1967.

Coser, Lewis. The Functions of Social Conflict, Ed. The Free Press, USA, 1964.

Dharendorf, Ralf. The Modern Social Conflict, Transaction Publishers, USA, 2008.

Domínguez, Roberto y García, Silvia. Introducción a la Teoría del Conflicto en las Organizaciones, Working Papers 48, Universidad Rey Juan Carlos, España, 2003.

Galtung, Johan. Theories of Conflict. Ed. University Press. USA, 2009. 
García Luís, Muñoz Diego y Gómez Juan. Aportes teóricos al concepto de conflicto social: una lectura desde las macro y microsociologías hasta los modelos integradores emergentes, Revista Virajes. $\mathrm{N}^{\circ}$ 8, Colombia, 2006, 17-47. Guiloff, Matías. El dilema del artículo $19 n^{\circ} 8$ inciso 2, Revista de Derecho, Universidad Católica del Norte, Año 18 - No 1, Chile, 2011, 147-169. Han, Byung Chul. Sobre el poder, Ed. Heder, España, 2016. Huntington, Samuel. El orden político en la sociedad del cambio, Paidós, España, 1979. Levinger, Matthew. Conflict Analysis: Understanding Causes, Unlocking Solutions, United States Institute of Peace Academy Guides edition, USA, 2013.

Lobos, Khaterine. Análisis de la nueva institucionalidad ambiental desde la reforma a la ley 19.300. Tesina. Universidad Católica de la Santísima Concepción, 2015.

Lorenzo, Pedro-Luis. Principales Teorías sobre el Conflicto Social. Revista Historia, Norba 15, España, 2001, 237-254.

Max-Neef, Manfred. Desarrollo a escala humana: Conceptos, aplicaciones y algunas reflexiones, Icaria Editorial, España, 1993.

Migdal, Joel. Estados débiles, Estados fuertes, Ed. Fondo Cultura Económica. México, 2011.

O’Donnell, Guillermo. Democracia, Agencia y Estado. Editorial Prometeo, Buenos Aires, 2010.

O’Leary, Rosemary. The Ethics of Dissent, Ed. CQ Press, USA, 2006.

Oszlak, Oscar. El Rol del Estado: Micro, Meso, Macro. Conferencia Dictada en el VI Congreso de Administración Pública Organizado por la Asociación Argentina de Estudios de Administración Pública y la Asociación de Administradores Gubernamentales, Resistencia del Chaco, Argentina, 2011, p.5.

Poulantzas, Nicos. Estado, Poder y Socialismo. Ed. Siglo XXI, México, 1979.

Rungruangsakorn, Carlos. El rol del Estado en los Conflictos Socioambientales en el Marco del Sistema de Evaluación de Impacto Ambiental Chileno, Tesis doctoral en Ciencia Sociales, mención Ciencia Política, Universidad Nacional de Cuyo, Argentina, 2018.

Silva, Germán. La teoría del conflicto. Un marco teórico necesario, Prolegómenos Derechos y Valores, vol. XI, $\mathrm{N}^{\circ}$ 22, Bógota, 2008, 29-43.

Soengas-Pérez, Xosé. The Role of the Internet and Social Networks in the Arab Uprisings an Alternative to Official Press Censorship. Comunicar, 41, España, 2013, 147-155.

TERRAM, Análisis, desafios y críticas a la nueva institucionalidad ambiental, XIV congreso CECADES, Universidad de Playa Ancha, Chile, 2011.

\section{Prensa}

El Ciudadano, "Sindicatos, parlamentarios y organizaciones crean comisión paralela para reforma al SEIA", https://www.elciudadano.cl/organizacion-social/parlamentarios-organizaciones-crean-comisionparalela-para-reforma-al-seia/09/28/, revisado el 5 de enero de 2019.

Gobierno de Chile, https://www.gob.cl/noticias/mandataria-crea-la-comision-asesora-presidencialpara-el-estudio-de-un-nuevo-sistema-de-evaluacion-de-impacto-ambiental-seia/, revisado 5 de enero de 2019.

TERRAM, Noticias, https:/ /www.terram.cl/2015/12/ongs-ambientales-renuncian-a-comision-asesorapresidencial-para-reforma-del-seia/, revisado el 5 de enero de 2019. 


\section{Documentos}

Cámara de Diputado de Chile, Segundo del Informe de la Comisión De Medio Ambiente y Bienes Nacionales, recaído en el proyecto de ley, en segundo trámite constitucional, que crea el Ministerio, el Servicio de Evaluación Ambiental y la Superintendencia del Medio Ambiente. BOLETÍN No 5947-1, 2009.

Cámara del Senado de Chile, Segundo informe de la Comisión de Medio Ambiente y Bienes Nacionales, noviembre 2009.

Comisión Sindical Cívico Parlamentaria, Informe de la Comisión Sindical Cívico Parlamentaria para la Reforma del SEIA, disponible en

bttp:/ / www.fima.cl/ wordpress/2016/08/10/infome-de-la-comision-sindical-civico-parlamentaria-para-la-reforma-delseial, revisado el 5 de enero de 2019.

Decreto supremo $N^{\circ} 271$, https://www.leychile.cl/Navegar?idNorma=15055, revisado 5 de enero de 2019.

Ley 19.300, Bases Generales del Medio Ambiente, https://www.leychile.cl/Navegar?idNorma=30667, revisado 5 de enero de 2019.

Ley de Presupuesto 2018, http://www.dipres.gob.cl/597/articles-172496_doc_pdf.pdf, revisado el 5 de enero de 2019. 